\title{
Ventricular Septal Defect after Blunt Trauma in a Case of Preexisting Prosthetic Mitral Valve
}

\author{
Bhargava Nishith', Mangukia Chirantan'1, Virmani Sanjula², Singh Harpreet ${ }^{3}$, \\ Satsangi K. Deepak ${ }^{3}$ \\ ${ }^{1}$ Cardiothoracic and Vascular Surgery (CTVS), G B Pant Hospital (GBPH), New Delhi, India \\ ${ }^{2}$ Department of Anesthesia, GBPH, New Delhi, India \\ ${ }^{3}$ Department of CTVS, GBPH, New Delhi, India \\ Email: drnishithbhargava@gmail.com
}

Received 10 October 2014; revised 7 November 2014; accepted 10 December 2014

Copyright (C) 2014 by authors and Scientific Research Publishing Inc.

This work is licensed under the Creative Commons Attribution International License (CC BY). http://creativecommons.org/licenses/by/4.0/

c) (i) Open Access

\begin{abstract}
We present a case of an isolated large ventricular septal defect (VSD) following blunt chest trauma in a motor vehicle accident in the patient with preexisting mechanical mitral valve. Transthoracic echocardiography revealed a large muscular VSD with significant left to right shunt along with septal edema. Surgical repair was performed in view of $Q p: Q s$ of 2.5 with significant hemodynamic instability despite intra-aortic balloon pump. The ventricular septal defect was found in apical muscular portion of the interventricular septum, which was closed through left ventriculotomy. We here discuss the possible mechanisms of damage and importance of timely surgery. To conclude, minor looking external injury might contain devastating damage inside, especially with patients on anti-coagulant therapy.
\end{abstract}

\section{Keywords}

Blunt Trauma Chest, Ventricular Septal Defect, Prosthetic Mitral Valve

\section{Introduction}

Cardiac injuries resulting from blunt chest trauma are usually because of high speed motor vehicle accidents. The severity of external injuries does not necessarily reflect the degree of cardiac trauma. Blunt chest trauma can cause a variety of cardiac injuries such as myocardial contusion, myocardial rupture, ventricular septal defect (VSD), pericardial trauma, valvar disruption and acute myocardial infarction. We report a case of post 
traumatic VSD in preexisting prosthetic mechanical mitral valve. Anti-coagulation therapy adversely affected the traumatized heart resulting in extensive septal contusion.

\section{Case Report}

A 24 year old man with diagnosis of severe rheumatic mitral stenosis underwent a mechanical mitral valve replacement (MVR) with a 29-mm ATS (Advancing The Standards, Minnesota) mechanical bi-leaflet valve with posterior chordal preservation in July 2012. Patient followed a smooth post-operative course with pulmonary pressure upon echocardiography regressing from $72 \mathrm{~mm} \mathrm{Hg}$ pre-operatively to $18 \mathrm{~mm} \mathrm{Hg}$ at 6 months follow up. NYHA class improved significantly from grade III (pre-operatively) to grade I (post-operatively) after 6 months.

Nearly one year later, the patient sustained blunt chest trauma in a motor vehicle accident with side on collision with a car. Patient complained of dyspnea, and was taken to the local hospital and was found in hypotensive shock. Patient was referred to our center on inotropic support for further management. Upon examination, patient was hypotensive, tachycardic, pale with feeble femoral pulses and absent peripheral pulses. Examination was negative for rib fracture, sternal in-drawing or palpable crepitus. Auscultation revealed a pan-systolic murmur at apical area with presence of valve click and bilateral basal crepitation affecting bilateral lower lobes. Urgent emergency room trans-thoracic echocardiography (TTE) was performed which showed a $2.6 \mathrm{~cm}$ ventricular septal defect (VSD) in apical muscular area with significant left to right shunt and Qp:Qs of 2.5, with significant septal edema. Coronary angiography revealed normal coronaries. International Normalized Ratio of the patient was found to be 2.68 on oral anticoagulation drug warfarin $2.5 \mathrm{mg}$ per day. Patient was soon shifted to ICU where he required intubation; step up in inotropic support and an intra-aortic balloon pump inserted in view of unstable hemodynamics. He was taken up for emergency surgery within 4 hours of hospital admission. Intraoperative transesophageal echocardiography (TEE) at the time of surgery revealed a normal functioning mechanical mitral valve (Figure 1), with large apical muscular VSD with significant left to right shunt (Figure 2(a)-(b)). Visualized antero-lateral wall of heart appeared to be contused.

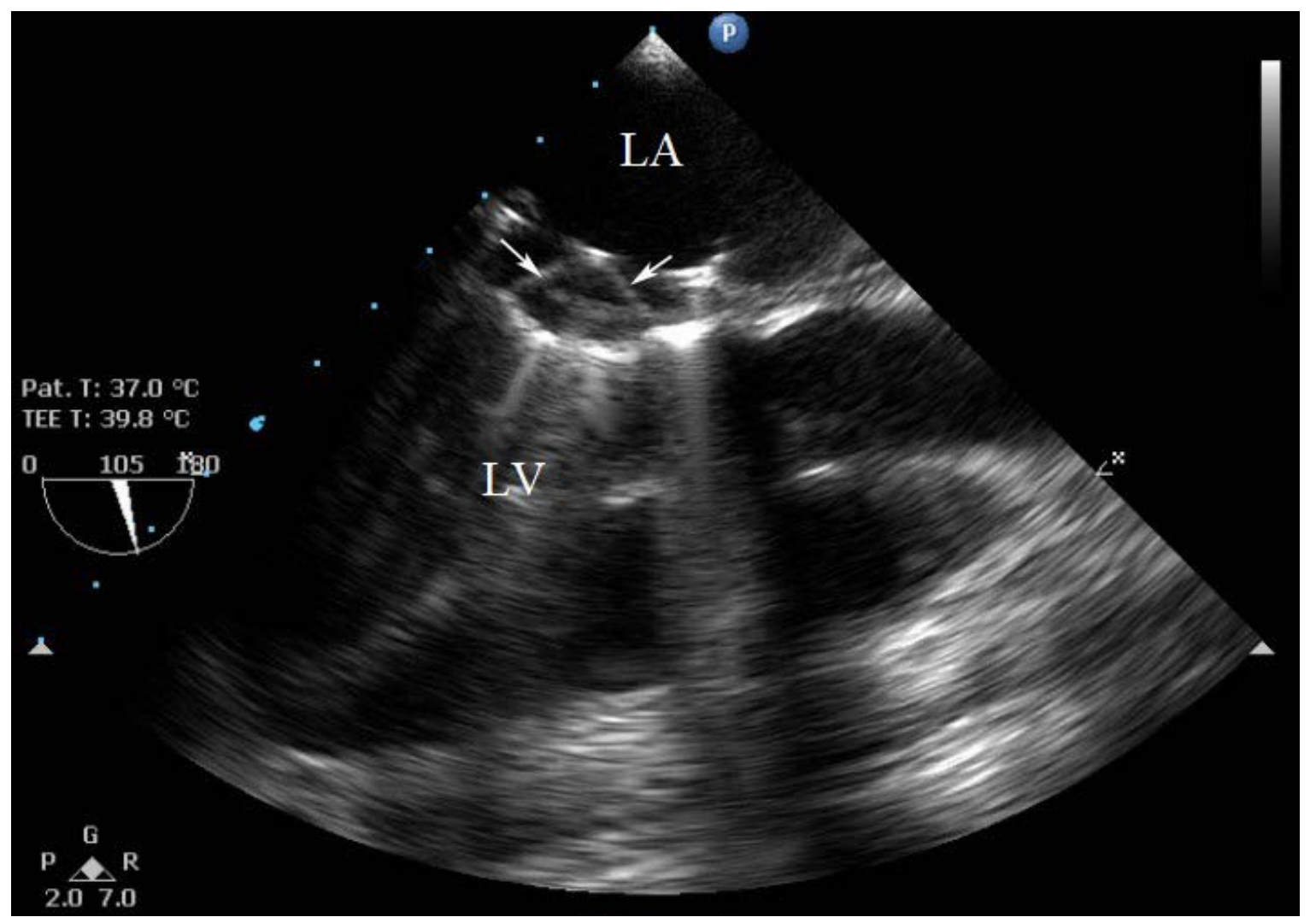

Figure 1. TEE image of prosthetic mitral valve-White arrow shows the normal moving prosthetic valve leaflets. 


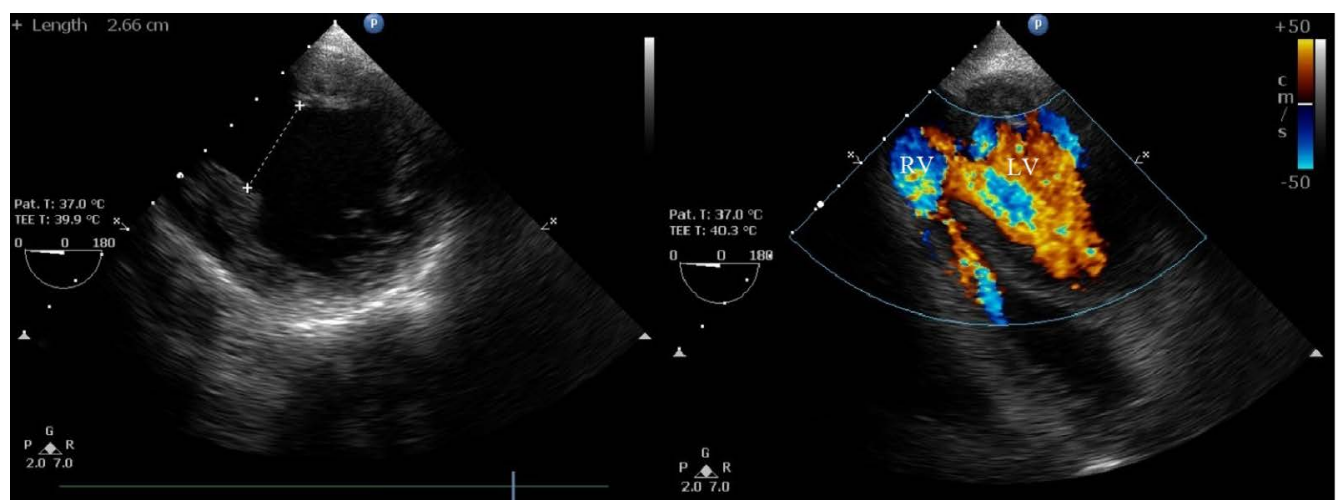

(a)

(b)

Figure 2. TEE Images of Apical Muscular VSD. (a) shows measurement of VSD (2.66 cm-upper left corner); (b) shows flow across VSD.

Cardiopulmonary bypass was established under moderate hypothermia with aortic and bicaval cannulation. A vent catheter was placed through the right superior pulmonary vein. Myocardial protection was performed with perfusion using cold-blood cardioplegia. VSD found to be inaccessible from right atrial approach. A left ventricular incision $4 \mathrm{~cm}$ long was put $3 \mathrm{~cm}$ away and parallel to the left anterior descending artery starting above the apex. Ventricular septal defect sized about $2.6 \times 2.7 \mathrm{~cm}$ was found to involve the apical muscular septum with edematous septum and unhealthy margins (Figure 3(a)). Dacron patch closure of the defect was performed with interrupted, pledgeted horizontal mattress 4-0 polypropylene sutures. The left ventricular incision was closed with PTFE felt buttressed with 4-0 polypropylene sutures (Figure 3(b)). The patient successfully weaned off cardiopulmonary bypass, TEE showed complete repair of the defect with fair biventricular function with significant septal edema. Patient shifted in ICU for further management, and succumbed to death on post-operative day one due to persistent low cardiac output syndrome.

\section{Discussion}

There are several case reports of VSD after penetrating and blunt chest trauma but during the literature review we found only one case report [1] of post traumatic VSD in presence of prosthetic mitral valve, signifying its rarity.

Cardiac contusion is the most frequent lesion of the heart observed after blunt chest trauma. Serious blunt injuries to the heart, followed by rupture of the ventricles or atria, lead to instantaneous pericardial tamponade and death, usually before hospital admission. Though, posttraumatic VSD don't follow such an acute path and give some time to the surgeon to intervene, close watch should be maintained. In our case the Post traumatic VSD deteriorated very rapidly which required urgent surgical intervention. The probable cause of the rapid deterioration was aggravation of septal contusion by anticoagulation therapy. Coronary artery dissection after trauma is also rare and usually occurs a few centimeters beyond the origin of the LAD causing extensive anterior wall infarction with the potential risk of left ventricular aneurysm formation [2]. In our case Coronary angiography was normal.

Various mechanisms have been described: rapid deceleration injury of the chest resulting in a thrust of the heart against the sternum; acute compression of the heart between the sternum and the spine; and acute contusion resulting in myocardial devascularization with subsequent necrosis and late perforation [1]. Ventricular septal rupture occurs most typically in late diastole or early systole when both the atrioventricular and semilunar valves are closed and the intraventricular pressures are high. Sudden elevation of pressure caused by the impact gives way to the rupture of the ventricular septum [3]. In literature, the most common localization of traumatic ventricular defect is in the muscular septum ([4] p. 5). Multiple septal rupture with damage to conduction system is also reported [6].

Kotrec Marian et al. found perimembranous type of VSD in their report describing post traumatic VSD with preexisting prosthetic mitral valve [1]. The case underwent surgical repair after 11 months and had multiple non-cardiac issues with stable hemodynamics. This appears fundamentally different from our case scenario. In 


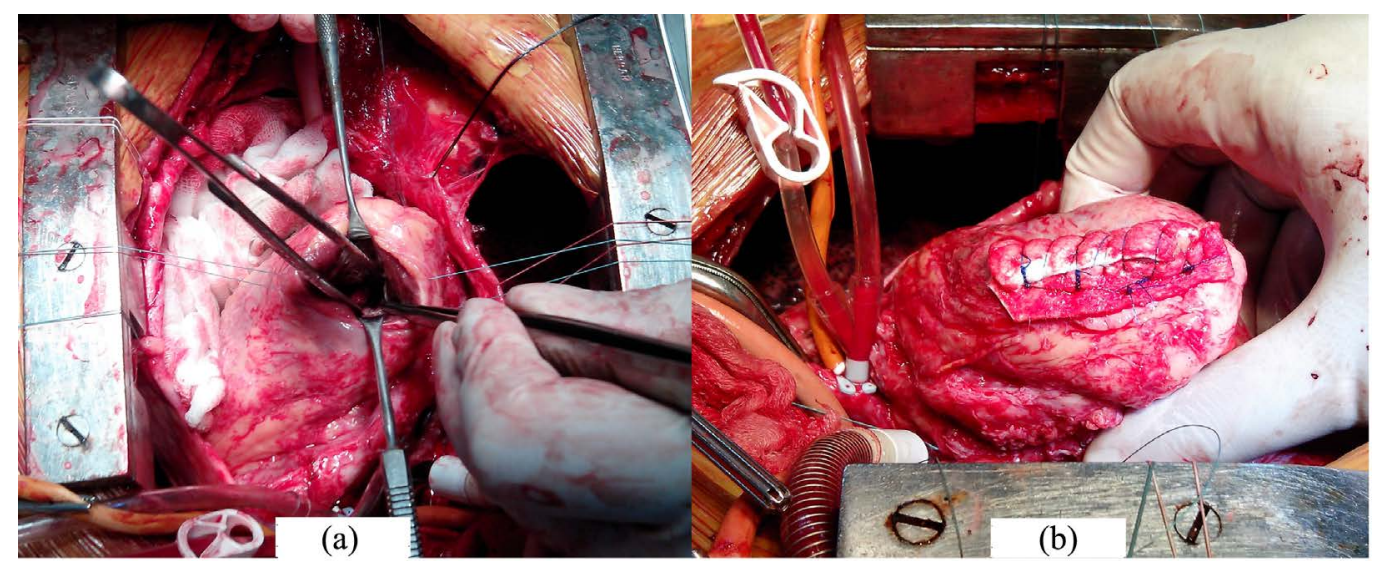

Figure 3. Intra-operative pictures. (a) shows the Left ventriculotomy incision with forceps inside the ventricular septal defect; (b) shows the closure of Left ventriculotomy incision with PTFE felt.

our case, muscular septum was affected the most and the patient had a rapid deterioration immediately after trauma and appeared that the contusion of the muscular septum, aggravated by ongoing anti-coagulation therapy was the principle cause behind apical muscular defect.

According to some authors, the initial small traumatic tear leads to secondary defect that is larger, which becomes apparent with delay [7]. In clinical practice, this warrants high vigilance even when initial cardiac assessments are negative for VSD. TTE should be performed as soon as possible when a new hemodynamic instability occurs or when there is a new pansystolic murmur.

Surgical closure is the treatment of choice and should be timed according to the patient's hemodynamic condition. Delayed closure of VSD can lead to deterioration of congestive heart failure. Current recommendations suggest repair if the Qp:Qs ratio exceeds 1.5 [1]. Surgery did not result a significant improvement in our case probably due to 1) high Qp:Qs ratio (2.5); 2) delayed presentation to our hospital; 3) contused septum, anterior and lateral wall; aggravation of contusion because of ongoing anticoagulation therapy; 4) Left Ventriculotomy (which was necessary to close the VSD) made an another hit to the already contused myocardium and 5) preexisting rheumatic heart disease.

\section{Conclusion}

We present the case of a patient having an apical muscular VSD following blunt chest trauma with preexistent mechanical mitral valve prosthesis with rapid hemodynamic deterioration and congestive heart failure. Minor looking external injury might contain devastating damage inside, especially with patients on anti-coagulant therapy. To our knowledge, similar co-occurrence is very rare.

\section{References}

[1] Kotrec, M., Jassal, D.S., Zieroth, S., Freed, D.H. and Tam, J.W. (2011) Ventricular Septal Defect as a Result of Direct Trauma from Mechanical Mitral Valve Prosthesis. Canadian Journal of Cardiology, 27, e21-e23.

[2] Cherng, W.-J., Bullard, M.J., Chang, H.-J. and Lin, F.-C. (1995) Diagnosis of Coronary Artery Dissection Following Blunt Chest Trauma by Transesophageal Echocardiography. The Journal of Trauma and Acute Care Surgery, 39, 772774. http://dx.doi.org/10.1097/00005373-199510000-00032

[3] Évora, P.R., Ribeiro, P.J., Brasil, J.C., Otaviano, A.G., Amaral, F.T., Reis, C.L., et al. (1985) Late Surgical Repair of Ventricular Septal Defect Due to Nonpenetrating Chest Trauma: Review and Report of Two Contrasting Cases. The Journal of Trauma and Acute Care Surgery, 25, 1007-1009. http://dx.doi.org/10.1097/00005373-198510000-00016

[4] Terui, G., Kaneko, K., Miura, M. and Kawazoe, K. (1997) Ventricular Septal Defect Secondary to Non-Penetrating Chest Trauma. Japanese Circulation Journal, 61, 951-953. http://dx.doi.org/10.1253/jcj.61.951

[5] Moront, M., Lefrak, E.A. and Akl, B.F. (1991) Traumatic Rupture of the Interventricular Septum and Tricuspid Valve: Case Report. The Journal of Trauma and Acute Care Surgery, 31, 134-136. http://dx.doi.org/10.1097/00005373-199101000-00026

[6] End, A., Rödler, S., Oturanlar, D., Müller, M., Jaskulka, R., Grabenwöger, F., et al. (1992) Surgery of Blunt Heart 
Trauma. Der Chirurg; Zeitschrift für alle Gebiete der operativen Medizen, 63, 641.

[7] Schaffer, R.B., Berdat, P.A., Seiler, C. and Carrel, T.P. (1999) Isolated Fracture of the Ventricular Septum after Blunt Chest Trauma. The Annals of Thoracic Surgery, 67, 843-844. http://dx.doi.org/10.1016/S0003-4975(99)00044-2 
Scientific Research Publishing (SCIRP) is one of the largest Open Access journal publishers. It is currently publishing more than 200 open access, online, peer-reviewed journals covering a wide range of academic disciplines. SCIRP serves the worldwide academic communities and contributes to the progress and application of science with its publication.

Other selected journals from SCIRP are listed as below. Submit your manuscript to us via either submit@scirp.org or Online Submission Portal.
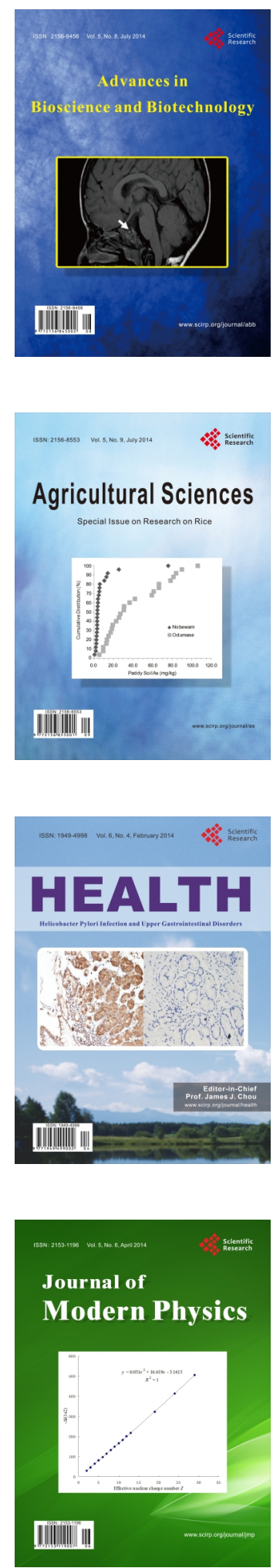
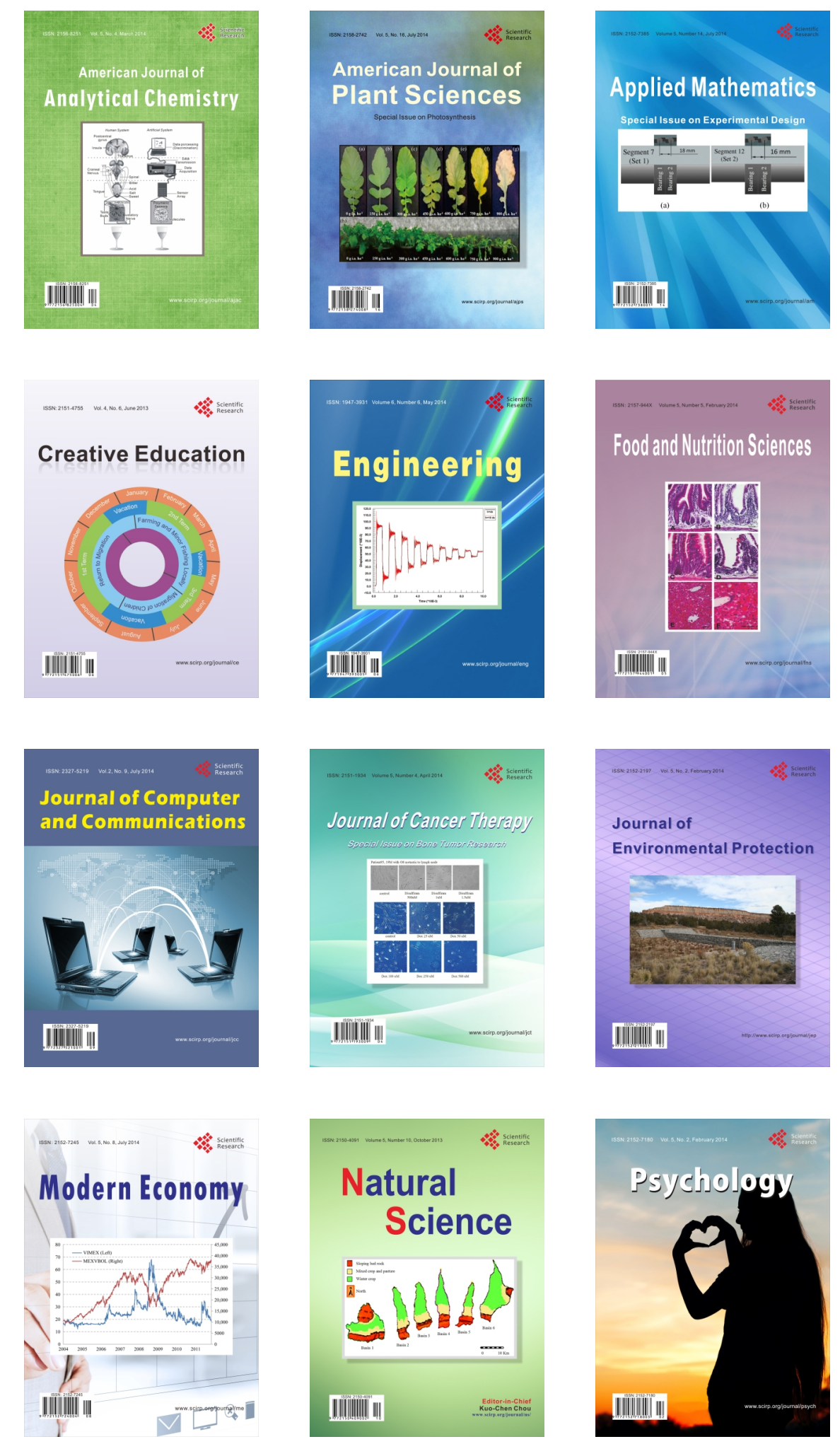